\title{
BMJ Open Association between end-of-life cancer care and immigrant status: a retrospective cohort study in Ontario, Canada
}

\author{
Anna Chu, ${ }^{1,2}$ Lisa Barbera, ${ }^{1,3,4}$ Rinku Sutradhar, ${ }^{1,5}$ Urun Erbas Oz, ${ }^{1}$ Erin O'Leary, ${ }^{1}$ \\ Hsien Seow (1) ${ }^{1,6}$
}

To cite: Chu A, Barbera L, Sutradhar R, et al. Association between end-of-life cancer care and immigrant status: a retrospective cohort study in Ontario, Canada. BMJ Open 2021;11:e042978. doi:10.1136/ bmjopen-2020-042978

- Prepublication history and supplemental material for this paper is available online. To view these files, please visit the journal online (http://dx.doi. org/10.1136/bmjopen-2020042978).

Received 23 July 2020 Accepted 17 May 2021

\section{Check for updates}

(c) Author(s) (or their employer(s)) 2021. Re-use permitted under CC BY-NC. No commercial re-use. See rights and permissions. Published by BMJ.

${ }^{1}$ ICES, Toronto, Ontario, Canada ${ }^{2}$ Department of Physical Therapy, University of Toronto, Toronto, Ontario, Canada ${ }^{3}$ Department of Oncology, University of Calgary, Calgary, Alberta, Canada

${ }^{4}$ Tom Baker Cancer Centre, Alberta Health Services, Calgary, Alberta, Canada

${ }^{5}$ Dalla Lana School of Public Health, University of Toronto, Toronto, Ontario, Canada

${ }^{6}$ Department of Oncology, McMaster University, Hamilton, Ontario, Canada

Correspondence to

Dr Hsien Seow;

seowh@mcmaster.ca

\section{ABSTRACT}

Objective To compare recent immigrants and long-term residents in Ontario, Canada, on established health service quality indicators of end-of-life cancer care.

Design Retrospective, population-based cohort study of cancer decedents between 2004 and 2015.

Setting Ontario, Canada.

Participants We grouped 13085 immigrants who arrived in Ontario in 1985 or later into eight major ethnic groups based on birth country, mother tongue and surname, and compared them to 229471 long-term residents who were $\geq 18$ years at the time of death.

Primary and secondary outcome measures Aggressive care, defined as a composite of $\geq 2$ emergency department visits, $\geq 2$ new hospitalisations or an intensive care unit admission within 30 days of death; and supportive care, defined as a physician house call within 2 weeks, or palliative nursing or personal support worker home visit within 6 months of death. Multivariable logistic regression was used to examine the association between immigration status and the odds of each main outcome.

Results Compared with long-term residents, immigrants overall and by ethnic group had higher rates of aggressive care $(13.7 \%$ vs $17.5 \%$, respectively; $p<0.001)$. Among immigrants, Southeast Asians had the highest use while White-Eastern and Western Europeans had the lowest. Supportive care use was similar between long-term residents and immigrants $(50.0 \%$ vs $50.5 \%$, respectively; $\mathrm{p}=0.36)$, though lower among Southeast Asians $(46.6 \%)$ and higher among White-Western Europeans (55.6\%). After adjusting for sociodemographic characteristics and comorbidities, immigrants remained more likely than longterm residents to receive aggressive care (OR: 1.15, 95\% $\mathrm{Cl} 1.09$ to 1.21), yet were less likely to receive supportive care (OR: $0.95,95 \% \mathrm{Cl} 0.91$ to 0.98).

Conclusions Among cancer decedents in Ontario, immigrants are more likely to use aggressive healthcare services at the end of life than long-term residents, while supportive care varies by ethnicity. Contributors to variation in end-of-life care require further study.

\section{INTRODUCTION}

Recently, there has been increasing attention to racial and ethnic inequities in many contexts including health and healthcare,
Strengths and limitations of this study

- Using health administrative data from a universal healthcare system, we conducted a populationbased study of all cancer decedents in Ontario, Canada, between 2004 and 2015.

- Established quality indicators of end-of-life cancer care were compared among long-term residents versus immigrants and among eight different ethnic groups.

- Studying the beliefs and preferences about endof-life care among immigrants of different ethnic groups is beyond the scope of this study.

- Immigrants who returned to their native country prior to death are not identified by our data sources, and thus are not included.

where reports from many countries have documented ethnic groups experiencing greater mortality and risk of some diseases, less access to healthcare and lower selfreported health. ${ }^{1-4}$ For immigrants, additional factors associated with migration, such as language barriers, new environments, limited family and social supports, limited awareness about how to navigate the healthcare system and diverse expectations and preferences with respect to healthcare, have the potential to further exacerbate health disparities, including at the end of life (EOL).

Previous studies of EOL care have found that immigrants in Canada and the USA are more likely to receive aggressive care, such as admission to an intensive care unit (ICU), mechanical ventilation and feeding tube placement at the EOL compared with non-immigrants. ${ }^{5} 6$ Whether these differences extend to immigrants dying of cancer, where arguably prognosis may be more foreseeable and opportunities for advanced care planning greater than with other conditions, is less well studied. Moreover, much of the 
prior research on ethnic disparities at the EOL focuses on Blacks, Whites and Latinos in the USA, where healthcare insurance and access is highly variable. ${ }^{78}$ Research on other ethnicities and immigrants in countries with universal healthcare is limited.

In Canada, a growing immigrant population makes it one of the world's most ethnically and culturally diverse high-income countries, with 7.5 million $(21.9 \%)$ Canadians reporting to be foreign born in the 2016 census. $^{9}$ Cancer also accounts for approximately $30 \%$ of all deaths, and with an ageing population, the incidence of cancer is expected to rise along with the number of deaths. ${ }^{10}$ As such, much effort has been put towards improving and measuring the quality of EOL care of Canadians over the last two decades. ${ }^{11-15}$ Palliative care when near death has been associated with less acute healthcare use and costs, and better quality of life of patients with cancer, including better symptom control, physician communication, emotional support and respectful treatment. ${ }^{16-20}$ Together, Canada's ethnic diversity and universal healthcare system make it an ideal setting for studying health services in multiethnic populations. Ontario, Canada is particularly suited for studying immigrant care because $51.1 \%$ of the country's immigrants live in the province. ${ }^{9}$

The objective of this study is to compare immigrants and Canadian-born/long-term residents of Ontario with a cancer cause of death on the use of both aggressive and supportive healthcare near the time of death. We hypothesised that in our cancer population, immigrants would receive more aggressive care and less supportive care than non-immigrants. As per the Andersen-Newman model of healthcare utilisation, use is explained by predisposing characteristics (eg, demographics, social structure, health beliefs), enabling resources (eg, community structure, personal means) and need. For our study, immigrants may have sociocultural predisposing factors that differ from the mostly Westernised biomedical approach found in Ontario's health system (eg, health beliefs that avoid discussions about death or refuse palliative or supportive care measures), which may affect their EOL care use. ${ }^{21}$

\section{METHODS}

\section{Study population}

We conducted a population-based retrospective cohort study of residents in Ontario, Canada, who died of cancer between 2004 and 2015 and were 18 years or older at the time of death. Cancer decedents were identified from the Registrar General of Ontario Vital Statistics Database, which contains information from the death certificates of all deaths registered in Ontario. The Ontario Cancer Registry, a population-based registry which captures information on over $90 \%$ of all incident cancer cases in Ontario, was used to determine the cancer diagnosis type. ${ }^{22}$ Immigrant status was determined through linkage to the Immigration, Refugees and Citizenship Canada Permanent Resident (IRCC-PR) database, which began in 1985 and thus only contains sociodemographic information about all immigrants who arrived in Ontario in 1985 or later, referred to as (recent) immigrants from here on. Immigrants identified in the IRCC-PR were then classified into eight major ethnic groups based on previously validated algorithms using their country of birth, mother tongue and surname. ${ }^{2324}$ Immigrants who landed in Ontario in 1985 or later were compared overall and by ethnic group with individuals born in Canada or who immigrated prior to 1985 (together termed 'long-term residents'), on established health service quality indicators of EOL cancer care.

\section{Quality indicators and data sources}

We examined both aggressive and supportive EOL quality care indicators previously identified to be important to patients with cancer and which were measurable using health administrative data. ${ }^{11} 1325$ Our primary aggressive care indicator was a composite of $\geq 2$ emergency department (ED) visits, $\geq 2$ new hospitalisations or an ICU admission within 30 days of death. Secondary aggressive care indicators studied were death in an acute care hospital, new hospital admissions, admission to an ICU and ED visits (all in the 30 days prior to death) and receipt of chemotherapy in the 2 weeks prior to death.

Our primary supportive care indicator was a composite of having $\geq 1$ palliative nursing or personal support worker home visit within 6 months of death or $\geq 1$ physician house call within 2 weeks of death. Prior research show that physician home visits very close to death were for palliative and supportive care purposes. ${ }^{26}$ Secondary supportive care indicators studied were the components of this composite indicator, and additionally, home visits in the 6 months prior to death by a registered nurse and personal support worker, regardless of palliative care intent.

Information about place of death, hospital and ICU admissions was obtained from the Canadian Institute for Health Information Discharge Abstract Database, which contains information from the discharge abstracts of all hospitals in Canada. ED visits were identified from the National Ambulatory Care Reporting System, which captures demographic and clinical information about visits to all EDs in Ontario. Receipt of intravenous chemotherapy and physician house calls were captured using the Ontario Health Insurance Plan Physician Claims database, and home visits identified from Ontario's Home Care Database. A summary of data sources for our study population and indicators is provided in online supplemental table 1. All data sets were linked using unique, encoded identifiers and analysed at ICES (formerly known as the Institute for Clinical Evaluative Sciences). ICES is an independent, non-profit research institute whose legal status under Ontario's health information privacy law allows it to collect and analyse healthcare and demographic data, without patient consent, for health system evaluation and improvement. 
Table 1 Baseline characteristics of study population, 2004-2015

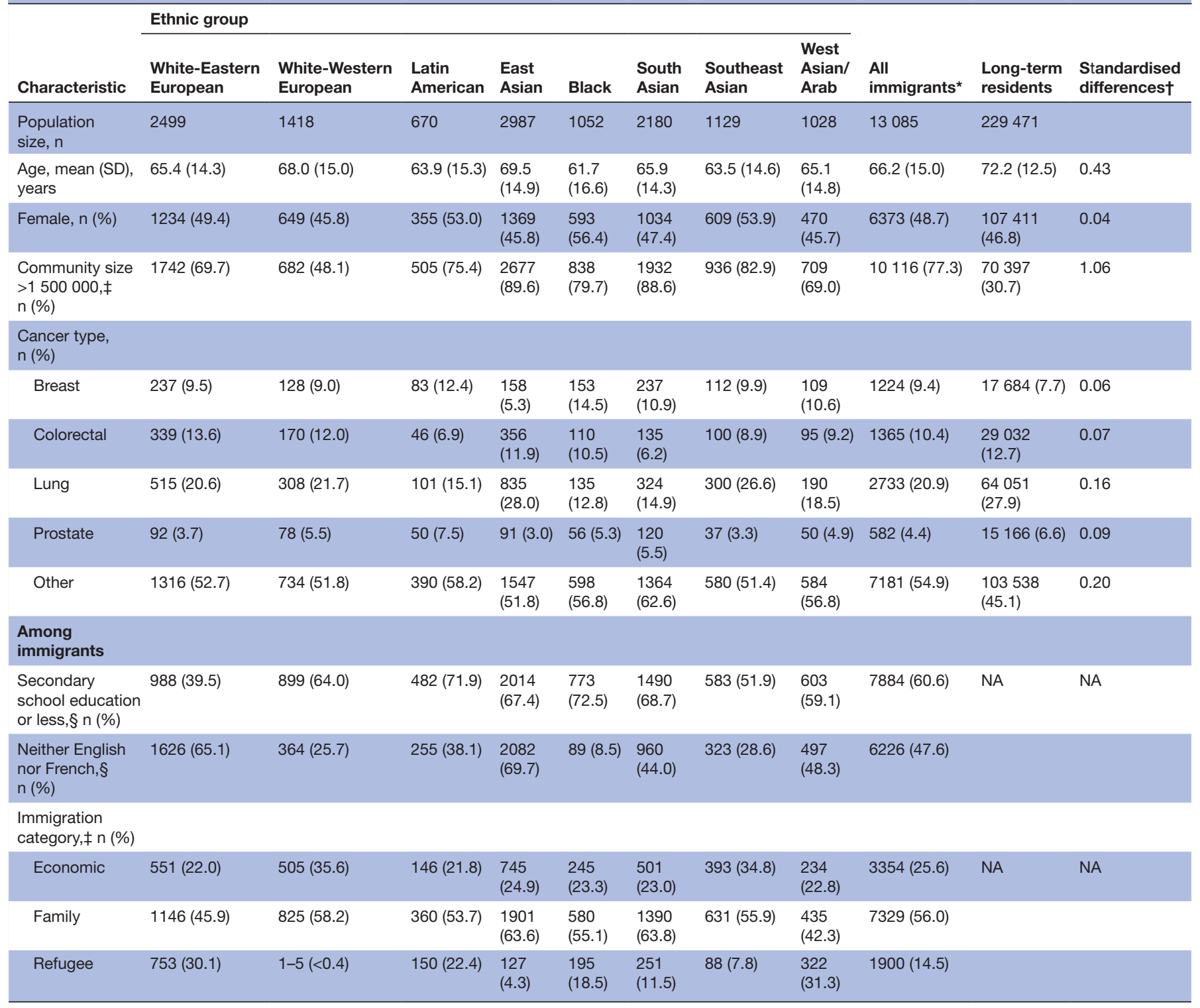

Ethnic groups are ordered by increasing adjusted risk of the composite indicator for aggressive care (defined as having at least two emergency department visits, two new hospitalisations or an intensive care unit (ICU) admission within 30 days of death).

*Includes 122 immigrants for whom ethnicity is unknown.

†Reported standardised differences are for comparisons of all immigrants versus long-term residents. P value $<0.001$ for comparison of all characteristics between individual ethnic groups.

fDue to space limitations, proportions for neighbourhood income quintile, smaller community sizes, non-economic/family/refugee immigration categories and Charlson score are not shown. Thus, categories shown do not add up to $100 \%$. Information on community size is missing for 10 immigrants and 172 long-term residents. $\S$ Education and language ability are at the time of application for immigration.

NA, not applicable.

\section{Patient and public involvement}

The quality indicators examined in this study are informed by prior research and the data sets used are encoded. Thus, patients were not invited to comment on the study design, consulted to interpret the results or invited to contribute to the writing or editing of this paper for readability or accuracy.

\section{Statistical analysis}

Data were summarised using mean (SD) for continuous variables and frequencies (\%) for categorical variables. Characteristics of the study population at the time of death among immigrants and long-term residents were compared using standardised differences. For immigrants overall and by ethnic group, we also examined education and language ability at the time of application for immigration, and immigration category (ie, economic, family, refugee or other).

Quality indicators were calculated as crude proportions. To account for differences in sociodemographics and comorbidities among ethnic groups and long-term residents, for our primary aggressive and supportive care measures only, we conducted multivariable logistic 


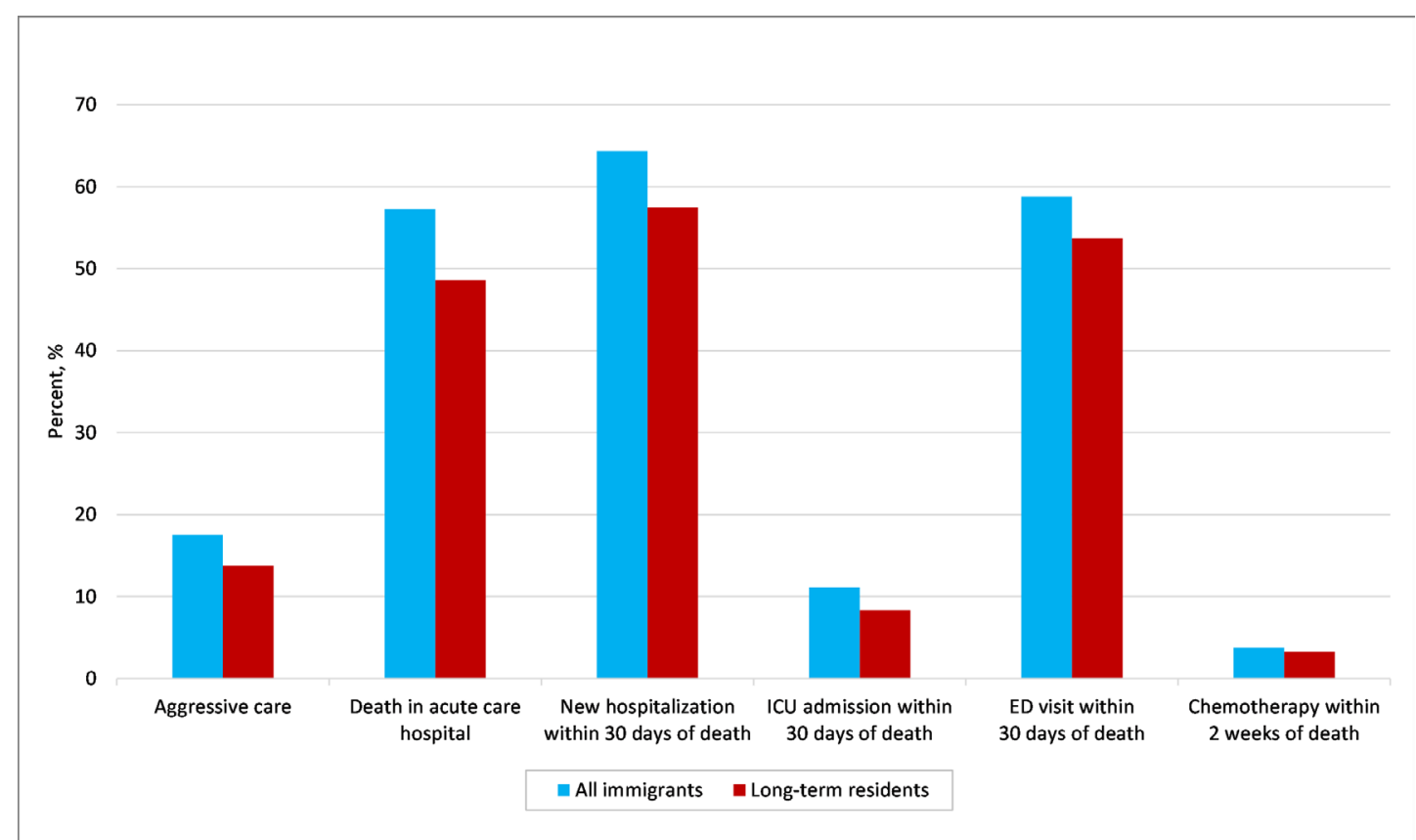

Figure 1 Aggressive care quality indicator rates by immigrant status, 2004-2015. The composite aggressive care indicator is defined as receipt of $\geq 2$ emergency department visits, $\geq 2$ new hospitalisations or an intensive care unit (ICU) admission within 30 days of death. ED, emergency department.

regression analyses, adjusting for characteristics of clinical significance or shown to be associated with these outcomes in prior studies including age, sex, Charlson score, cancer type, neighbourhood income quintile, community size, health region and year of death. ${ }^{11}$ Cancer type was determined at the time of diagnosis, and all remaining covariates were measured at the time of death. Patients with missing income quintile, community size or health region information $(<0.05 \%$ of both immigrants and long-term residents) were excluded from the regression analyses. Patients with a missing Charlson score due to no hospital admission during the observation period were grouped with patients with a zero score. Comparing immigrant ethnic groups only, we additionally adjusted for education, language ability, time since immigration and immigration category (economic, family, refugee or other). Since our study included deaths over a 12-year period, we also examined whether the effect of immigration status on receiving aggressive and supportive care changed over time by adding a two-way interaction term between immigration status and year of death into our regression models.

All analyses were conducted at ICES using SAS V.9.4 (SAS Institute). Two-sided $\mathrm{p}$ values $<0.05$ were considered significant.

\section{RESULTS}

Between 2004 and 2015, we identified 242556 individuals with a cancer cause of death, of whom 13085 $(5.4 \%)$ were recent immigrants (table 1$)$. East Asians and White-Eastern Europeans made up the largest immigrant ethnic groups $(n=2987(22.8 \%)$ and $n=2499(19.1 \%)$, respectively), whereas Latin Americans were the smallest $(\mathrm{n}=670(5.1 \%))$. Compared with long-term residents, recent immigrants were younger at the time of death, comprised a greater proportion of females and were more likely to live in low-income neighbourhoods and urban communities. Lung cancer was the leading cause of death for both immigrants and long-term residents.

Among recent immigrants, 60.6\% $(n=7884)$ had less than secondary school education and $47.6 \%(n=6226)$ had neither English nor French language ability at the time of applying for immigration, though these varied among ethnic groups. By the time of their death, $74.1 \%(n=9701)$ had resided in Canada for over 10 years, including $80.3 \%$ of Latin Americans and 78.6\% White-Western Europeans compared with $65.9 \%$ of West Asians /Arabs and $67.6 \%$ of South Asians.

\section{Aggressive care}

Compared with long-term residents, immigrants overall and by ethnic group had generally higher rates of aggressive healthcare use on both the composite (immigrants overall, $17.5 \%$ vs long-term residents, $13.7 \%$; $<<0.001)$ and individual indicators $(\mathrm{p}<0.05$ for all) (figure 1 and online supplemental table 2). Among immigrants, West Asians/Arabs, Southeast Asians and South Asians had the highest composite aggressive care rates (range 20.2\%-20.9\%). However, East Asians also had high rates of death in an acute care hospital and new hospital admissions within 30 days of death. Overall, White-Eastern and Western Europeans had the lowest rates of aggressive care on the individual and composite indicators (14.3\% and $15.1 \%$, respectively). 


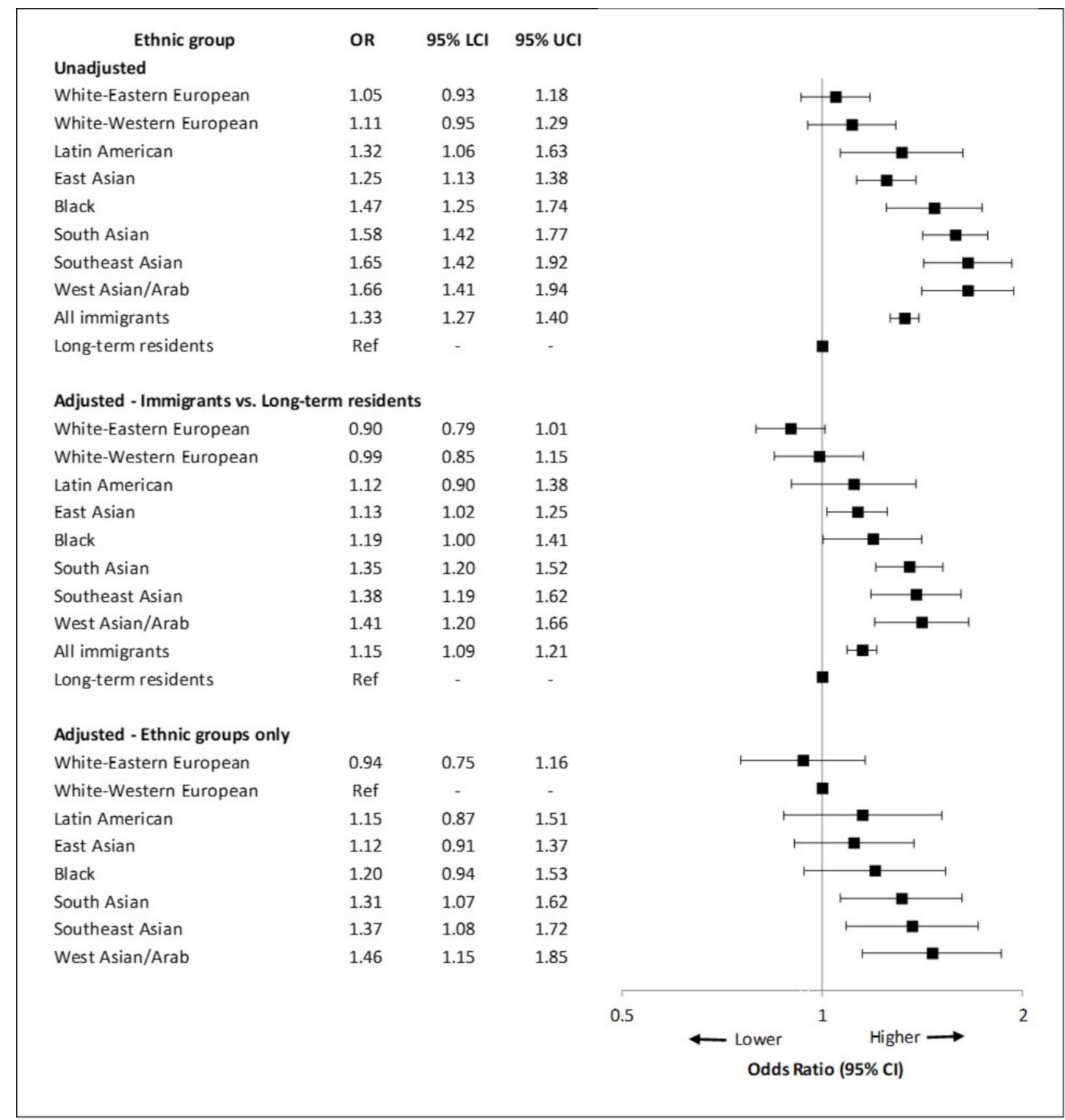

Figure 2 ORs for receiving aggressive care. Ethnic groups are listed in order of increasing adjusted risk of receiving aggressive care versus long-term residents, defined as having $\geq 2$ emergency department visits, $\geq 2$ new hospitalisations or an intensive care unit admission within 30 days of death. Models for all immigrants versus long-term residents were computed separately from individual ethnic groups versus long-term residents. Immigrants of unknown ethnicity are excluded from analyses. Covariates included in adjusted models for immigrants versus long-term residents were age, sex, Charlson score, cancer type, neighbourhood income quintile, community size, health region and year of death. Adjusted models for ethnic groups only additionally adjusted for education, language ability, time since immigration and immigration category. $\mathrm{LCl}$, lower $\mathrm{Cl}$; $\mathrm{UCl}$, upper Cl.

In unadjusted regression analyses, all ethnic groups except White-Eastern and Western Europeans were at significantly greater risk than long-term residents of receiving aggressive care, defined as our composite indicator (figure 2 and online supplemental table $3, \mathrm{p}<0.05$ ). After adjustment, immigrants overall, as well as East Asians, South Asians, Southeast Asians and West Asians/ Arabs, remained more likely than long-term residents to receive aggressive care (OR: 1.15, 95\% CI 1.09 to 1.21 for immigrants overall). The effect of immigration status also did not change over time $(\mathrm{p}=0.54$ for interaction with year of death). Among immigrants only, additional adjustment for education, language ability, time since immigration and immigration category resulted in minimal change in ethnic groups' likelihood of receiving aggressive care relative to each other.

\section{Supportive care}

Immigrants overall and long-term residents had similar rates of supportive care on both the composite and individual indicators $(50.5 \%$ vs $50.0 \%$, respectively, for composite; $\mathrm{p}=0.36$ ) (figure 3 and online supplemental table 2). By ethnic group, rates of supportive care varied with White-Western Europeans having the highest use on 


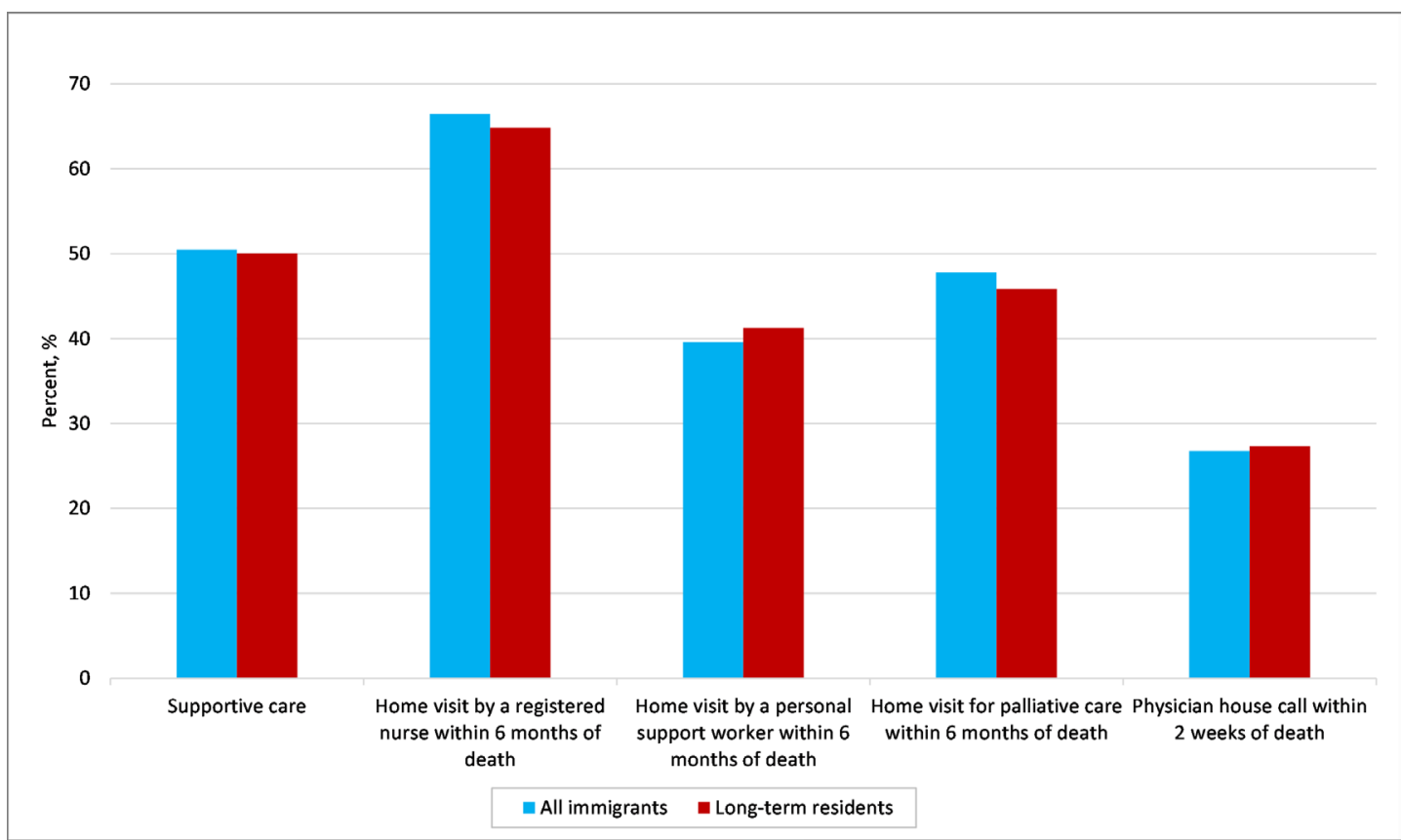

Figure 3 Supportive care quality indicator rates by immigrant status, 2004-2015. The composite supportive care indicator is defined as receipt of $\geq 1$ physician house call within 2 weeks of death, or $\geq 1$ palliative nursing or personal support worker home visit within 6 months of death.

the composite indicator $(55.6 \%)$ and Southeast Asians having the lowest $(46.6 \%)$. On the four individual indicators, White-Eastern and Western Europeans, Latin Americans and West Asians/Arabs generally had the highest rates, including close to $70 \%$ of patients receiving a home visit by a registered nurse during the 6 months prior to death, while East Asians again had the lowest rates.

Although in unadjusted analyses, the odds of immigrants overall receiving supportive care was not significantly different than long-term residents (OR: 1.02, $95 \%$ CI 0.98 to 1.06 ), they were less likely to do so after adjustment (OR: $0.95,95 \%$ CI 0.91 to 0.98 ) (figure 4 and online supplemental table 4). Differences after adjustment were attributable to differences in age, sex, neighbourhood income quintile and Charlson score. Furthermore, the effect of immigration status did not change over time $(p=0.41$ for interaction with year of death). Among ethnic groups, Southeast Asians, Blacks and East Asians were the least likely to receive supportive care (ORs: $0.75,95 \%$ CI 0.66 to $0.85 ; 0.82$, $95 \%$ CI 0.72 to $0.93 ; 0.89,95 \%$ CI 0.82 to 0.96 , respectively vs long-term residents), and White-Western Europeans were most likely (OR: $1.16,95 \%$ CI 1.03 to 1.30 vs long-term residents). Similar to aggressive care, the relative likelihood of receiving supportive care among ethnic groups did not change after adjustment for immigration factors.

\section{DISCUSSION}

In this study of cancer decedents' utilisation of both aggressive and supportive care at the EOL in Ontario, Canada, between 2004 and 2015, we found that after accounting for differences in sociodemographics and comorbidities, recent immigrants were $15 \%$ more likely to use aggressive care (defined by ED visits and new hospital or ICU admissions) and 5\% less likely to receive supportive care (defined by physician house calls and palliative nursing/personal support worker home visits) than long-term residents. Although overall differences in supportive care may not be clinically significant, care also varied among ethnic groups with Southeast Asians having a 25\% lower and White-Western Europeans having a 16\% higher likelihood of receiving supportive care.

Our findings are consistent with studies of patients with any cause of death. Among Ontario residents both with and without cancer, recent immigrants have been reported to be more likely than long-term residents to die in an acute care hospital and be admitted to a hospital and ICU in their last month of life. ${ }^{6}$ Additionally, decedents born in Europe were not at significantly different risk of dying in an ICU than long-term residents, while those born in Southeast Asia and South Asia were more likely to do so. In the USA, patients of Black, Hispanic and Asian ethnic groups both with and without cancer have also been reported to be more likely to receive aggressive care at the EOL, including death in a hospital, hospital and ICU admission, and use of mechanical ventilation, cardiopulmonary resuscitation and feeding tubes. ${ }^{5}$ 27-32 They are also less likely to access palliative care, particularly hospice care, and are more likely to access it closer to death and to disenrol. ${ }^{81-34}$ Non-hospice palliative care is less well studied and has focused on beliefs, discussions about EOL care and advanced care planning. ${ }^{78}$ Additionally, few of these studies differentiate between immigrants 


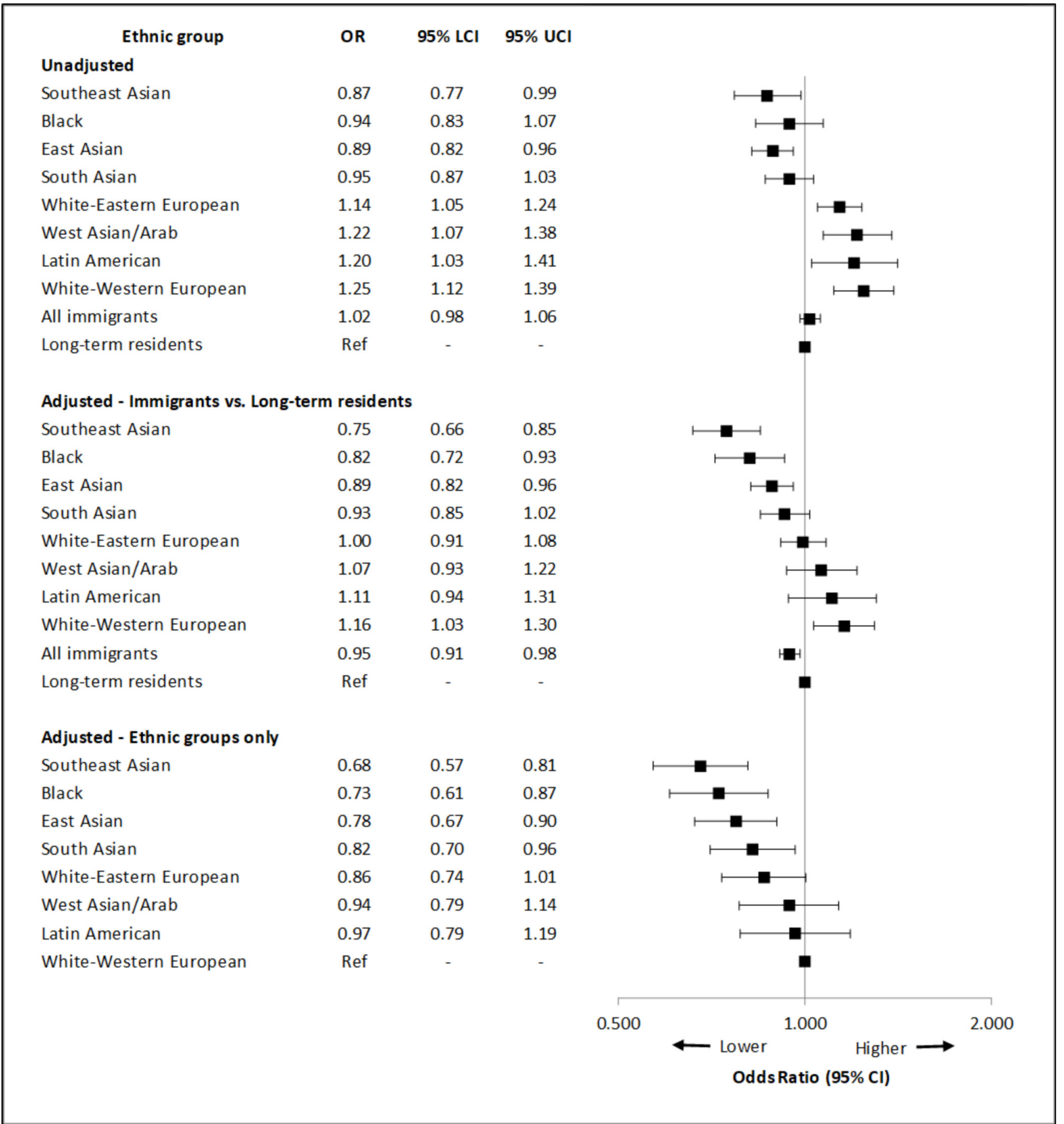

Figure 4 ORs for receiving supportive care. Ethnic groups are listed in order of increasing adjusted risk of receiving supportive care versus long-term residents, defined as having $\geq 1$ physician house call within 2 weeks of death, or $\geq 1$ palliative nursing or personal support worker home visit within 6 months of death. Models for all immigrants versus long-term residents were computed separately from individual ethnic groups versus long-term residents. Immigrants of unknown ethnicity are excluded from analyses. Covariates included in adjusted models for immigrants versus long-term residents were age, sex, Charlson score, cancer type, neighbourhood income quintile, community size, health region and year of death. Adjusted models for ethnic groups only additionally adjusted for education, language ability, time since immigration and immigration category. LCl, lower $\mathrm{Cl}$; UCl, upper $\mathrm{Cl}$.

and non-immigrants, and may be influenced by the ability to pay for care. Our results suggest that in the context of cancer and in a universal healthcare system, where ongoing treatment near death is of questionable benefit, immigrants in Ontario are similarly more likely to use aggressive care health services and less likely to receive supportive care at the EOL as patients dying of other causes.
Several factors may explain our findings. Communication barriers, degree of acculturation, knowledge of and preference for care options at the EOL and beliefs about advanced care planning may all be contributory. $^{29}$ 35-39 Although $74 \%$ of immigrants in our study had resided in Canada for over 10 years prior to death, challenges encountered in settling in a new country on arrival may persist or be exacerbated when near death. 
With almost half of immigrants lacking English or French language ability when applying for immigration, their understanding of medical terms and care options, and capacity or readiness to communicate care wishes may influence the care they receive. As immigrants are generally healthier on arrival to Canada (the healthy immigrant effect), when compared with non-immigrants, they may also be less familiar with the healthcare system and services available at the EOL. ${ }^{40-42}$

Beyond the scope of this study was the study of beliefs and preferences about EOL care. Although many studies have reported patients with cancer prefer to die at home, the generalisability of these studies to immigrant populations is unknown. In the USA, a greater proportion of Blacks and Hispanics with cancer have consistently been found to prefer aggressive care near death when compared with Whites. ${ }^{7283639}$ Differences between ethnic groups and long-term residents in care preferences and circumstances that would enable EOL care at home may thus influence care accessed and received, especially when residing in a country with less familiarity and potentially fewer social supports than their country of origin. ${ }^{43-46}$

Also unclear is the relationship between aggressive and supportive care. Many previous studies have found that supportive care, including physician continuity and greater and earlier use of palliative and home care services, is associated with lower use of acute care services at the EOL. ${ }^{16-20} 264748$ This supports our finding of WhiteWestern Europeans' high rates of receipt of supportive care and low rates of aggressive care. However, this pattern was not consistently observed among other ethnic groups, and other factors need consideration. Although much effort has been dedicated to increasing access to palliative and home care services in Ontario and Canada, it may still be insufficient for some immigrants to manage at home when near death even when preferred. ${ }^{12} 1415$ Particularly, whether economic class immigrants or refugees have adequate family or social supports and prefer to be cared for at home could not be examined using our data sources and thus requires further study. Regardless, healthcare providers and administrators should be aware of factors that may influence immigrants' use of health services at the EOL, such as language barriers, culture, available social supports and knowledge about care options including their risks and benefits, such that their interactions with immigrants and their caregivers may facilitate informed decision-making and improved quality of life at this time.

This study is limited by our inability to classify the longterm resident cohort into similar ethnic groups as immigrants or identify people who immigrated to Ontario prior to 1985 . However, we estimate that over $95 \%$ are of White ethnicity and approximately $17 \%$ are immigrants who arrived prior to $1985 .{ }^{49}$ Relatedly, the algorithms used to classify immigrants into ethnic groups also have limitations and it is likely that some immigrants may have been misclassified, though we believe the combining of two algorithms reduced this number. Our results may also be influenced by the salmon bias which hypothesises that when immigrants get older or sick, they return to their region of origin, and thus are not captured in population health studies. ${ }^{50-52}$ Although this bias has been shown to contribute to the mortality advantage among some immigrants in the UK, Hispanics in the USA and internal migrants in China, its effect on differences in EOL care is unknown, and is likely to vary between ethnic groups. ${ }^{51-53}$ We also did not control for stage of cancer at diagnosis. With some belief that immigrants present at later stages, this delay impacts patient preferences for treatment and time for advanced care planning. Lastly, whether our findings are generalisable to immigrants in other provinces or countries also requires further investigation.

\section{CONCLUSIONS}

This study highlights differences in care between longterm residents and immigrants with cancer near death. Although immigrants overall were more likely to receive aggressive care and less likely to receive supportive care than long-term residents after accounting for differences in sociodemographic characteristics and comorbidities, the care received varied by ethnicity. The relationship between aggressive and supportive care within ethnic groups was also unclear, and further study is required to better understand contributors to these differences and whether their needs at the EOL are being met.

Twitter Hsien Seow @HSeowPhD

Acknowledgements Parts of this material are based on data and information compiled and provided by the Ministry of Health and Long-Term Care (MOHLTC), the Ontario Registrar General (ORG), Cancer Care Ontario (CCO), Immigration, Refugees and Citizenship Canada (IRCC) and the Canadian Institute for Health Information $(\mathrm{ClHI})$. The original source of information on deaths from the ORG is Service0ntario.

Contributors AC conceived the study, participated in the study design and interpretation of results, and drafted the manuscript. HS and LB conceived the study, participated in the study coordination, study design, acquisition of data and interpretation of results, and provided feedback on the manuscript. RS participated in the study design and interpretation of results, and provided feedback on the manuscript. UEO participated in the study design, performed the analysis and provided feedback on the manuscript. EOL participated in the study design and study coordination, and provided feedback on the manuscript. All authors read and approved the final manuscript. HS and UEO had full access to all the data in the study and take responsibility for the integrity of the data and the accuracy of the data analysis.

Funding This work was supported by the Canadian Cancer Society Research Institute via the Canadian Centre for Applied Research in Cancer Control (grant number: 2015-703549). The study was supported by the British Columbia Cancer Agency and by ICES (formerly known as the Institute for Clinical Evaluative Sciences), which is funded by an annual grant from the Ontario Ministry of Health and Long-Term Care (MOHLTC).

Disclaimer The analyses, opinions, results and conclusions reported in this article are those of the authors and are independent of the ICES, MOHLTC, the funding sources, ORG, Ministry of Government Services, CCO, IRCC and CIHI. No endorsement by ICES, the Ontario MOHLTC, CCO, IRCC or CIHI is intended or should be inferred.

Competing interests None declared.

Patient consent for publication Not required.

Ethics approval This study was approved by the Hamilton Integrated Research Ethics Board, a joint board of St Joseph's Healthcare Hamilton, Hamilton Health 
Sciences and McMaster University's Faculty of Health Sciences, and follows the STROBE guidelines for the reporting of observational studies.

Provenance and peer review Not commissioned; externally peer reviewed.

Data availability statement Data may be obtained from a third party and are not publicly available. The data set from this study is held securely in coded form at ICES. While data sharing agreements prohibit ICES from making the data set publicly available, access may be granted to those who meet prespecified criteria for confidential access, available at www.ices.on.ca/DAS. The full data set creation plan and underlying analytic code are available from the authors upon request, understanding that the programs may rely upon coding templates or macros that are unique to ICES.

Supplemental material This content has been supplied by the author(s). It has not been vetted by BMJ Publishing Group Limited (BMJ) and may not have been peer-reviewed. Any opinions or recommendations discussed are solely those of the author(s) and are not endorsed by BMJ. BMJ disclaims all liability and responsibility arising from any reliance placed on the content. Where the content includes any translated material, BMJ does not warrant the accuracy and reliability of the translations (including but not limited to local regulations, clinical guidelines, terminology, drug names and drug dosages), and is not responsible for any error and/or omissions arising from translation and adaptation or otherwise.

Open access This is an open access article distributed in accordance with the Creative Commons Attribution Non Commercial (CC BY-NC 4.0) license, which permits others to distribute, remix, adapt, build upon this work non-commercially, and license their derivative works on different terms, provided the original work is properly cited, appropriate credit is given, any changes made indicated, and the use is non-commercial. See: http://creativecommons.org/licenses/by-nc/4.0/.

\section{ORCID iD}

Hsien Seow http://orcid.org/0000-0001-6701-1714

\section{REFERENCES}

1 Public Health Agency of Canada. Key health inequalities in Canada. A national portrait, 2018. Available: https://www.canada.ca/content/ dam/phac-aspc/documents/services/publications/science-research/ key-health-inequalities-canada-national-portrait-executive-summary/ hir-full-report-eng.pdf

2 Fiscella K, Sanders MR. Racial and ethnic disparities in the quality of health care. Annu Rev Public Health 2016;37:375-94.

3 American College of Physicians. Racial and ethnic disparities in health care, updated 2010: policy paper. Available: https://www. acponline.org/acp_policy/policies/racial_ethnic_disparities_2010.pdf

4 Kristiansen M, Razum O, Tezcan-Güntekin H, et al. Aging and health among migrants in a European perspective. Public Health Rev 2016;37:20.

5 Shen MJ, Prigerson HG, Tergas Al, et al. Impact of immigrant status on aggressive medical care counter to patients' values near death among advanced cancer patients. J Palliat Med 2019;22:34-40.

6 Yarnell CJ, Fu L, Manuel D, et al. Association between immigrant status and end-of-life care in Ontario, Canada. JAMA 2017;318:1479-88.

7 LoPresti MA, Dement F, Gold HT. End-Of-Life care for people with cancer from ethnic minority groups. Am J Hosp Palliat Care 2016;33:291-305.

8 Johnson KS. Racial and ethnic disparities in palliative care. J Palliat Med 2013:16:1329-34.

9 Statistics Canada. Focus on geography series, 2016 census. statistics Canada Catalogue No. 98-404-X2016001, 2017. Available: https://www12.statcan.gc.ca/census-recensement/2016/as-sa/fogsspg/Facts-can-eng.cfm? Lang=Eng\&GK=CAN\&GC=01\&TOPIC $=7$

10 Canadian Cancer Statistics Advisory Committee. Canadian cancer statistics; 2019.

11 Barbera L, Seow H, Sutradhar R, et al. Quality of end-of-life cancer care in Canada: a retrospective four-province study using administrative health care data. Curr Oncol 2015;22:341-55.

12 Canadian Cancer Society. Right to care: palliative care for all Canadians. Toronto, ON; 2016.

13 Earle CC, Park ER, Lai B, et al. Identifying potential indicators of the quality of end-of-life cancer care from administrative data. J Clin Oncol 2003;21:1133-8.

14 Ontario HQ. Palliative care at the end of life; 2019.

15 Quality End-of-Life Care Coalition of Canada. Blueprint for action 2010 to 2020. Ottawa, ON; 2010.
16 Ziegler LE, Craigs CL, West RM, et al. Is palliative care support associated with better quality end-of-life care indicators for patients with advanced cancer? A retrospective cohort study. BMJ Open 2018;8:e018284.

17 Seow H, Barbera L, Howell D, et al. Using more end-of-life homecare services is associated with using fewer acute care services: a population-based cohort study. Med Care 2010;48:118-24.

18 Sutradhar R, Barbera L, Seow H-Y. Palliative homecare is associated with reduced high- and low-acuity emergency department visits at the end of life: a population-based cohort study of cancer decedents. Palliat Med 2017;31:448-55.

19 Almaawiy U, Pond GR, Sussman J, et al. Are family physician visits and continuity of care associated with acute care use at end-of-life? a population-based cohort study of homecare cancer patients. Palliat Med 2014;28:176-83.

20 Kavalieratos D, Corbelli J, Zhang D, et al. Association between palliative care and patient and caregiver outcomes: a systematic review and meta-analysis. JAMA 2016;316:2104-14.

21 Andersen RM. Revisiting the behavioral model and access to medical care: does it matter? J Health Soc Behav 1995;36:1-10.

22 Clarke EA, Marrett LD KN. Cancer registration in Ontario: a computer approach. In: Jensen OM, Parkin DM, MacLennan R, et al, eds. Cancer registration principles and methods. Lyon, France: IARC Publications, 1991: 246-57.

23 Rezai MR, Maclagan LC, Donovan LR, et al. Classification of Canadian immigrants into visible minority groups using country of birth and mother tongue. Open Med 2013;7:85-93.

24 Shah BR, Chiu M, Amin S, et al. Surname Lists to identify South Asian and Chinese ethnicity from secondary data in Ontario, Canada: a validation study. BMC Med Res Methodol 2010;10:42.

25 Henson LA, Edmonds P, Johnston A, et al. Population-Based quality indicators for end-of-life cancer care: a systematic review. JAMA Oncol 2020;6:142-50.

26 Tanuseputro P, Beach S, Chalifoux M, et al. Associations between physician home visits for the dying and place of death: a population-based retrospective cohort study. PLoS One 2018;13:e0191322.

27 Brown CE, Engelberg RA, Sharma R, et al. Race/Ethnicity, socioeconomic status, and healthcare intensity at the end of life. $J$ Palliat Med 2018;21:1308-16.

28 Loggers ET, Maciejewski PK, Paulk E, et al. Racial differences in predictors of intensive end-of-life care in patients with advanced cancer. J Clin Oncol 2009;27:5559-64.

29 Orlovic M, Smith K, Mossialos E. Racial and ethnic differences in end-of-life care in the United States: evidence from the health and retirement study (HRS). SSM - Population Health 2019;7:100331.

30 Ornstein KA, Roth DL, Huang J, et al. Evaluation of racial disparities in hospice use and end-of-life treatment intensity in the REGARDS cohort. JAMA Netw Open 2020;3:e2014639.

31 Smith AK, Earle CC, McCarthy EP. Racial and ethnic differences in end-of-life care in fee-for-service Medicare beneficiaries with advanced cancer. J Am Geriatr Soc 2009;57:153-8.

32 Unroe KT, Greiner MA, Johnson KS, et al. Racial differences in hospice use and patterns of care after enrollment in hospice among Medicare beneficiaries with heart failure. Am Heart $J$ 2012;163:987-93.

33 Ngo-Metzger Q, Phillips RS, McCarthy EP. Ethnic disparities in hospice use among Asian-American and Pacific Islander patients dying with cancer. J Am Geriatr Soc 2008;56:139-44.

34 Wang S-Y, Hsu SH, Aldridge MD, et al. Racial differences in health care transitions and hospice use at the end of life. J Palliat Med 2019;22:619-27.

35 Barwise A, Cheville A, Wieland ML, et al. Perceived knowledge of palliative care among immigrants to the United States: a secondary data analysis from the health information national trends survey. Ann Palliat Med 2019;8:451-61.

36 Garrido MM, Harrington ST, Prigerson HG. End-Of-Life treatment preferences: a key to reducing ethnic/racial disparities in advance care planning? Cancer 2014;120:3981-6.

37 Jonnalagadda S, Lin JJ, Nelson JE, et al. Racial and ethnic differences in beliefs about lung cancer care. Chest 2012;142:1251-8.

38 Kwak J, Haley WE. Current research findings on end-of-life decision making among racially or ethnically diverse groups. Gerontologist 2005;45:634-41.

39 Smith AK, McCarthy EP, Paulk E, et al. Racial and ethnic differences in advance care planning among patients with cancer: impact of terminal illness acknowledgment, religiousness, and treatment preferences. J Clin Oncol 2008;26:4131-7.

40 Lai DWL, Chau SBY. Predictors of health service barriers for older Chinese immigrants in Canada. Health Soc Work 2007;32:57-65. 
41 Lu C, Ng E. Healthy immigrant effect by immigrant category in Canada. Health Rep 2019;30:3-11.

42 McDonald JT, Kennedy S. Insights into the 'healthy immigrant effect': health status and health service use of immigrants to Canada. Soc Sci Med 2004;59:1613-27.

43 Alonso-Babarro A, Bruera E, Varela-Cerdeira M, et al. Can this patient be discharged home? Factors associated with at-home death among patients with cancer. J Clin Oncol 2011;29:1159-67.

44 Gu X, Cheng W, Cheng M, et al. The preference of place of death and its predictors among terminally ill patients with cancer and their caregivers in China. Am J Hosp Palliat Care 2015;32:835-40.

45 Higginson IJ, Sen-Gupta GJ. Place of care in advanced cancer: a qualitative systematic literature review of patient preferences. $J$ Palliat Med 2000;3:287-300.

46 Stajduhar KI, Allan DE, Cohen SR, et al. Preferences for location of death of seriously ill hospitalized patients: perspectives from Canadian patients and their family caregivers. Palliat Med 2008;22:85-8.

47 Seow H, Barbera L, Pataky R, et al. Does increasing home care nursing reduce emergency department visits at the end of life? a population-based cohort study of cancer decedents. J Pain Symptom Manage 2016;51:204-12.
48 Wright CM, Youens D, Moorin RE. Earlier initiation of communitybased palliative care is associated with fewer unplanned hospitalizations and emergency department presentations in the final months of life: a population-based study among cancer decedents. $J$ Pain Symptom Manage 2018;55:745-54.

49 Tu JV, Chu A, Rezai MR, et al. The incidence of major cardiovascular events in immigrants to Ontario, Canada: the CANHEART immigrant study. Circulation 2015;132:1549-59.

50 Abraído-Lanza AF, Dohrenwend BP, Ng-Mak DS, et al. The Latino mortality paradox: a test of the "salmon bias" and healthy migrant hypotheses. Am J Public Health 1999;89:1543-8.

51 Turra CM, Elo IT. The impact of salmon bias on the Hispanic mortality advantage: new evidence from social security data. Popul Res Policy Rev 2008;27:515-30.

52 Wallace M, Kulu H. Can the salmon bias effect explain the migrant mortality advantage in England and Wales? Popul Space Place 2018;24:e2146.

53 Lu Y, Qin L. Healthy migrant and salmon bias hypotheses: a study of health and internal migration in China. Soc Sci Med 2014;102:41-8. 